\title{
Uncertainty in the Future Distribution of Tropospheric Ozone over West Africa due to Variability in Anthropogenic Emissions Estimates between 2025 and 2050
}

\author{
J. E. Williams and P. F. J. van Velthoven \\ Chemistry and Climate Division, Royal Netherlands Meteorological Institute, 3730 AE De Bilt, The Netherlands \\ Correspondence should be addressed to J. E. Williams, williams@knmi.nl
}

Received 19 April 2011; Revised 26 July 2011; Accepted 18 August 2011

Academic Editor: Gregory S. Jenkins

Copyright (C) 2011 J. E. Williams and P. F. J. van Velthoven. This is an open access article distributed under the Creative Commons Attribution License, which permits unrestricted use, distribution, and reproduction in any medium, provided the original work is properly cited.

Particle and trace gas emissions due to anthropogenic activity are expected to increase significantly in West Africa over the next few decades due to rising population and more energy intensive lifestyles. Here we perform 3D global chemistry-transport model calculations for 2025 and 2050 using both a "business-as-usual" (A1B) and "clean economy" (B1) future anthropogenic emission scenario to focus on the changes in the distribution and uncertainties associated with tropospheric $\mathrm{O}_{3}$ due to the various projected emission scenarios. When compared to the present-day troposphere we find that there are significant increases in tropospheric $\mathrm{O}_{3}$ for the $\mathrm{A} 1 \mathrm{~B}$ emission scenario, with the largest increases being located in the lower troposphere near the source regions and into the Sahel around $15-20^{\circ} \mathrm{N}$. In part this increase is due to more efficient $\mathrm{NO}_{x}$ re-cycling related to increases in the background methane concentrations. Examining the uncertainty across different emission inventories reveals that there is an associated uncertainty of up to $\sim 20 \%$ in the predicted increases at 2025 and 2050. For the upper troposphere, where increases in $\mathrm{O}_{3}$ have a more pronounced impact on radiative forcing, the uncertainty is influenced by transport of $\mathrm{O}_{3}$ rich air from Asia on the Tropical Easterly Jet.

\section{Introduction}

West Africa (WA) is already one of the most densely populated regions of the African continent and thus is subject to high gaseous and particulate emissions associated with anthropogenic activities such as transport, energy production, biofuel use, industrial processes, and biomass burning (BB). For instance, high concentrations of tropospheric carbon monoxide $(\mathrm{CO})$, nitrogen oxides $\left(\mathrm{NO}_{x}\right)$, and volatile organic compounds (VOCs) have recently been measured in the lower troposphere (LT) near Lagos, Nigeria $\left(6.4^{\circ} \mathrm{N}, 3.4^{\circ} \mathrm{E}\right)$, indicating that large urban conurbations have a direct influence on regional air quality in WA [1]. The population of WA is expected to double to 170 million inhabitants by 2050 [2] which will result in associated increases in such emissions. The region is also subject to unique meteorological variability [3] which influences the long-range transport both into and out of the region of pollutants from, for example, large-scale $\mathrm{BB}$ practices in southern Africa during the West African Monsoon which are active during June-July-August (JJA) [4]. Therefore, any increases in land-based and sea-based emissions have the potential to influence the troposphere over a large region of Equatorial Africa (EA) and, thus, the oxidizing capacity of the tropical troposphere, where a dominant fraction of chemical oxidation occurs because of the locally high photochemical activity, humidity, and air temperatures.

Although recent advances have been made in understanding the physical and chemical processes affecting the troposphere over West Africa (e.g., [5]), significant uncertainties and biases remain with respect to reproducing the chemical composition of the African troposphere using large-scale chemistry-transport models (CTMs) and chemistry-climate models (CCMs) [6]. Major uncertainties arise from the selection and development of parameterizations describing convective transport [7], lightning activity [8], biogenic activity [9], and emission estimates related to $\mathrm{BB}[10]$. 
Estimates of the future trend in anthropogenic emissions, for example, for the timeline 2000-2050, vary depending on the likelihood that effective legislation is introduced regionally to tackle growing air-quality issues. This has led to the development of a variety of emission scenarios [11] with both increasing (A1B, "business-as-usual") and decreasing (B1, "clean economy") global totals where, up till 2007, the trend in global anthropogenic emissions is thought to have exceeded the A1B scenario [12]. Although the A1B scenario can be considered to be the most realistic estimate provided in the Special Report on Emission Scenarios (SRES, [11]), the recent economic slowdown is thought to have dampened regional emissions for, for example, Europe, although the effect for WA remains uncertain. This has consequences for climate by introducing both perturbations in the radiative forcing (RF) of the atmosphere due to increased tropospheric ozone $\left(\mathrm{O}_{3}\right)$ [13] and the subsequent influence on atmospheric lifetimes of long-lived greenhouse gases such as methane $\left(\mathrm{CH}_{4}\right)$. Here, we present simulations for the year 2025 and 2050 using both the A1B and B1 emission scenarios and compare the resulting perturbations in important tropospheric pollutants and oxidants with those simulated for the year 2003, with a special emphasis on tropospheric $\mathrm{O}_{3}$. We also quantify the uncertainty introduced into predictions of future tropospheric $\mathrm{O}_{3}$ distribution caused by the different assumptions entering emission inventories.

\section{Experimental Setup and Emission Inventories}

For the purpose of this study, we use the 3D global CTM TM4, which has recently participated in a number of modeling studies focusing on EA and the tropical troposphere over the Atlantic Ocean [4, 7-9]. Simulations were performed as part of the EU-integrated project QUANTIFY (Quantifying the Climate Impact of Global and European Transport Systems, http://www.pa.op.dlr.de/quantify/), whose principle focus was to investigate the influence of future transport emissions on climate and air quality. The model was run at a horizontal resolution of $3^{\circ} \times 2^{\circ}$ using 34 vertical levels and driven using operational forecast data provided by the European Centre for Medium-Range Weather Forecasting (ECMWF) using an update frequency of 6 hours. TM4 uses the modified CBM4 chemical mechanism [14] which includes $\mathrm{CO}-\mathrm{CH}_{4}-\mathrm{NO}_{x}-\mathrm{SO}_{x}$ chemistry. Photolysis is calculated using an efficient parameterization, with modifications to account for attenuation above cloud [15]. To differentiate the influence of increasing anthropogenic emissions on tropospheric $\mathrm{O}_{3}$ from possible trends in meteorological variables, we adopt the meteorology for the year 2003 throughout the study, which has been used for previous model intercomparisons (e.g., [16, 17]). These intercomparison studies have shown that TM4 exhibits chemical changes for 2003 that are close to an ensemble model mean using a range of state-of-the-art CTMs using the current presentday setup [17]. A one-year spin-up period is performed for all simulations using identical emission inventories and ECMWF meteorology for the year 2002.
Anthropogenic emissions from non-transport sources (including biofuel use) were taken from the EDGAR32FT2000 inventory [18] and scaled to the respective future emission scenarios [11]. Emissions for road transport, shipping, and aviation were taken from the latest recommendations as provided in the EU-QUANTIFY project [19-21]. The non-transport emissions are segregated with respect to month to capture the changing latitudinal distribution of BB activity, whereas those related to transport are annual averages. The BB contribution is accounted for by adopting the Global Fire Emission Database version 1 (GFEDv1) estimates for 2000 distributed using average fire activity for the period 1997-2002 [22]. This year is considered to be an average year in terms of annual BB activity therefore does not bias the simulations due to, for example, El Nino signals. Biogenic emissions of isoprene and soil $\mathrm{NO}_{\mathrm{x}}$ originate from online simulations with the EMAC CCM [23] averaged between 1998-2005. Injection heights are applied when introducing emissions to account for, for example, chimney stacks and pyrogenic convection during $\mathrm{BB}$ [24]. Lightening $\mathrm{NO}_{x}$ is scaled to a global total of 5 TgN/yr [25].

For the future simulations, anthropogenic $\mathrm{NO}_{x}, \mathrm{CO}$, $\mathrm{SO}_{2}$ and nonmethane hydrocarbon emissions are prescribed using estimates based on the A1B and B1 emission scenarios. No changes in $\mathrm{BB}$, biogenic, or lightning emissions are applied. To account for the continuous increase in global $\mathrm{CH}_{4}$ concentrations, albeit with significant interannual and decadal variability (e.g., [26]), the surface mixing ratios are fixed at $\sim 1.99 \mathrm{ppmv}$ and $\sim 2.40 \mathrm{ppmv}$ for 2025 and 2050, respectively, which assumes an average growth rate of $2 \mathrm{ppbv} / \mathrm{yr}^{-1}$ [27]. The potential changes in the overhead stratospheric $\mathrm{O}_{3}$ column are not accounted for, where the total column is constrained using satellite measurements for 2003. The present and future emission inventories are applied globally rather than just for the African continent.

\section{The Distribution and Growth in Anthropogenic $\mathrm{NO}_{x}$ Emissions for West Africa}

The annual distribution of anthropogenic $\mathrm{NO}_{x}$ emissions across WA and Sub-Saharan Africa for the present day (2003) is shown in Figure 1, where the contributions from non-transport and transport emission sources are shown separately with the integrated total from all transport sectors being projected directly onto the surface. It can be seen that the majority of non-transport emissions occur in the latitudinal range $5-10^{\circ} \mathrm{N}$. Within this latitudinal band, the distribution of non-transport $\mathrm{NO}_{x}$ is rather homogeneous with respect to longitude as a cumulative sum of both industrial and $\mathrm{BB}$ emissions is shown, as provided in the emission inventory. The distribution of urban conurbations can be clearly seen in the distribution of transport $\mathrm{NO}_{x}$ shown in Figure 1(b), with many of the major cities with large road transport emissions being located on the southern coastline of WA (e.g., Accra, Ghana $\left(5.5^{\circ} \mathrm{N}, 0.2^{\circ} \mathrm{W}\right)$; Monrovia, Liberia $\left(6.3^{\circ} \mathrm{N}, 10.8^{\circ} \mathrm{W}\right)$; Porto-Nova, Benin $\left.\left(6.5^{\circ} \mathrm{N}, 2.6^{\circ} \mathrm{E}\right)\right)$. The 


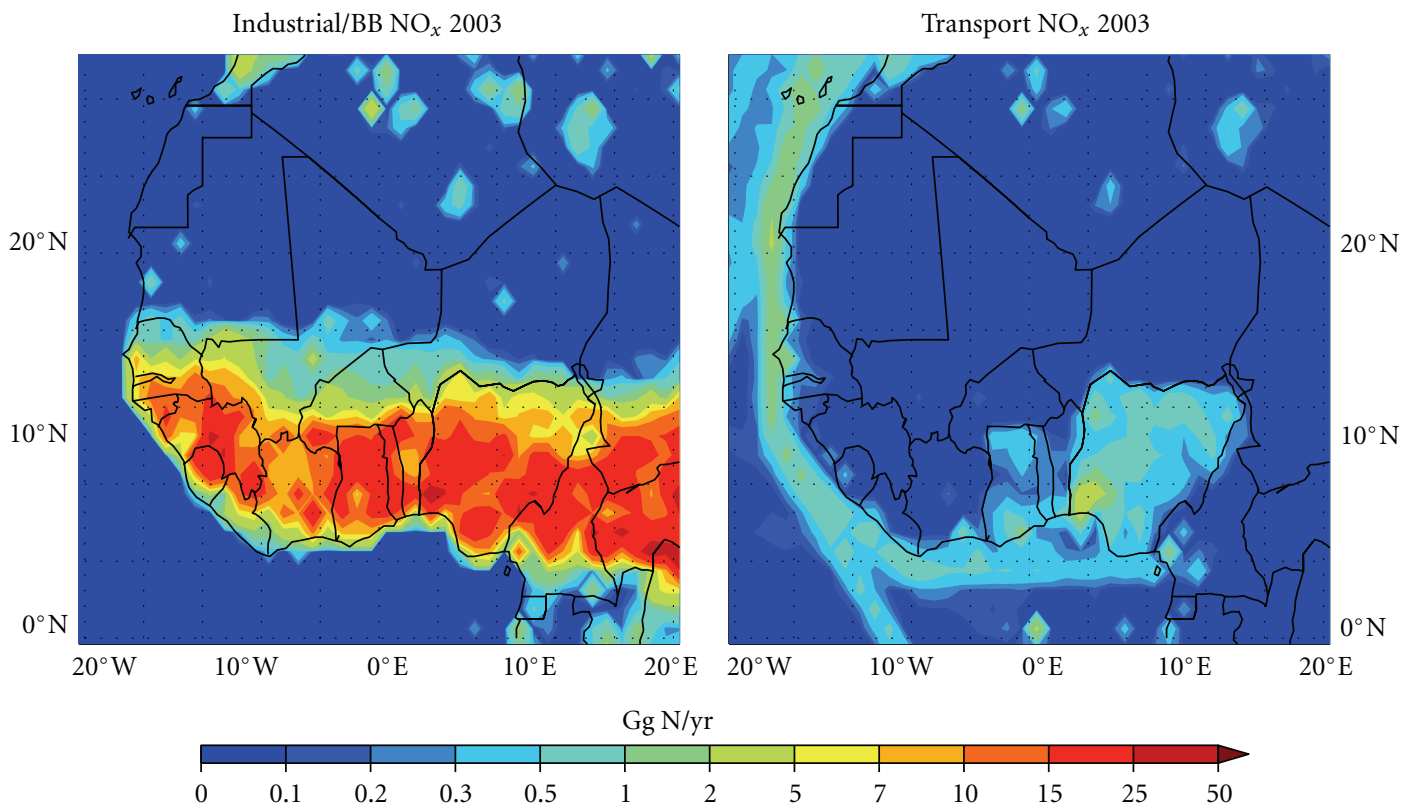

FIGURE 1: The annual distribution of anthropogenic $\mathrm{NO}_{x}$ emissions for 2003 in West Africa. The left panel shows non-transport-related NO${ }_{x}$ emissions including biomass burning emissions, and the right panel shows transport-related $\mathrm{NO}_{x}$ emissions.

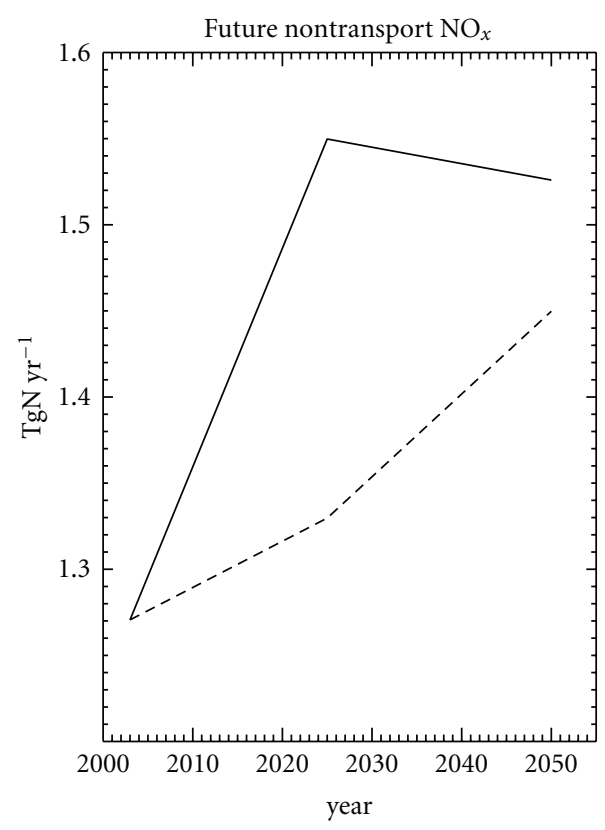

(a)

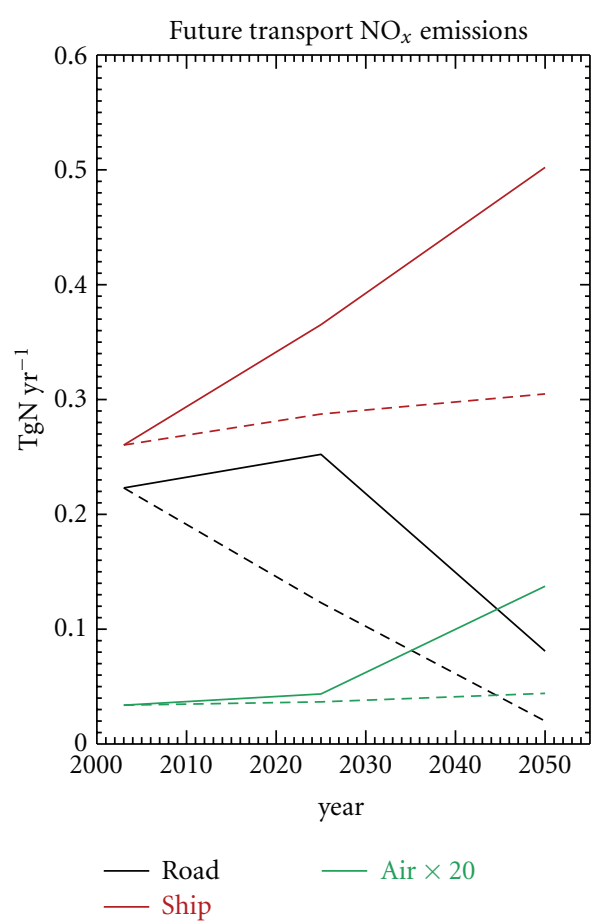

(b)

FIgURE 2: The evolution of (i) non-transport- and (ii) transport-based anthropogenic $\mathrm{NO}_{x}$ emissions for West $\mathrm{Africa}\left(0-30^{\circ} \mathrm{N}, 20^{\circ} \mathrm{W}-10^{\circ} \mathrm{E}\right)$ for the timeline 2000-2050. Both the A1B (solid line) and B1 (dashed line) future emission scenarios are shown.

importance of shipping for introducing appreciable $\mathrm{NO}_{x}$ emissions into the pristine Marine Boundary layer near the coastline is also visible.

The increase in annual $\mathrm{NO}_{x}$ emissions for the $\mathrm{A} 1 \mathrm{~B}$ and $\mathrm{B} 1$ emission scenarios over the timeline 2000-2050 are shown in Figure 2, as integrated between $0^{\circ}-30^{\circ} \mathrm{N}$ and $23^{\circ} \mathrm{W}-10^{\circ} \mathrm{E}$. The non-transport contribution clearly dominates, being approximately twice than of the corresponding transport contribution. For the Al scenario, there is an increase of $\sim 25 \%$ until 2025 in the non-transport component, after 

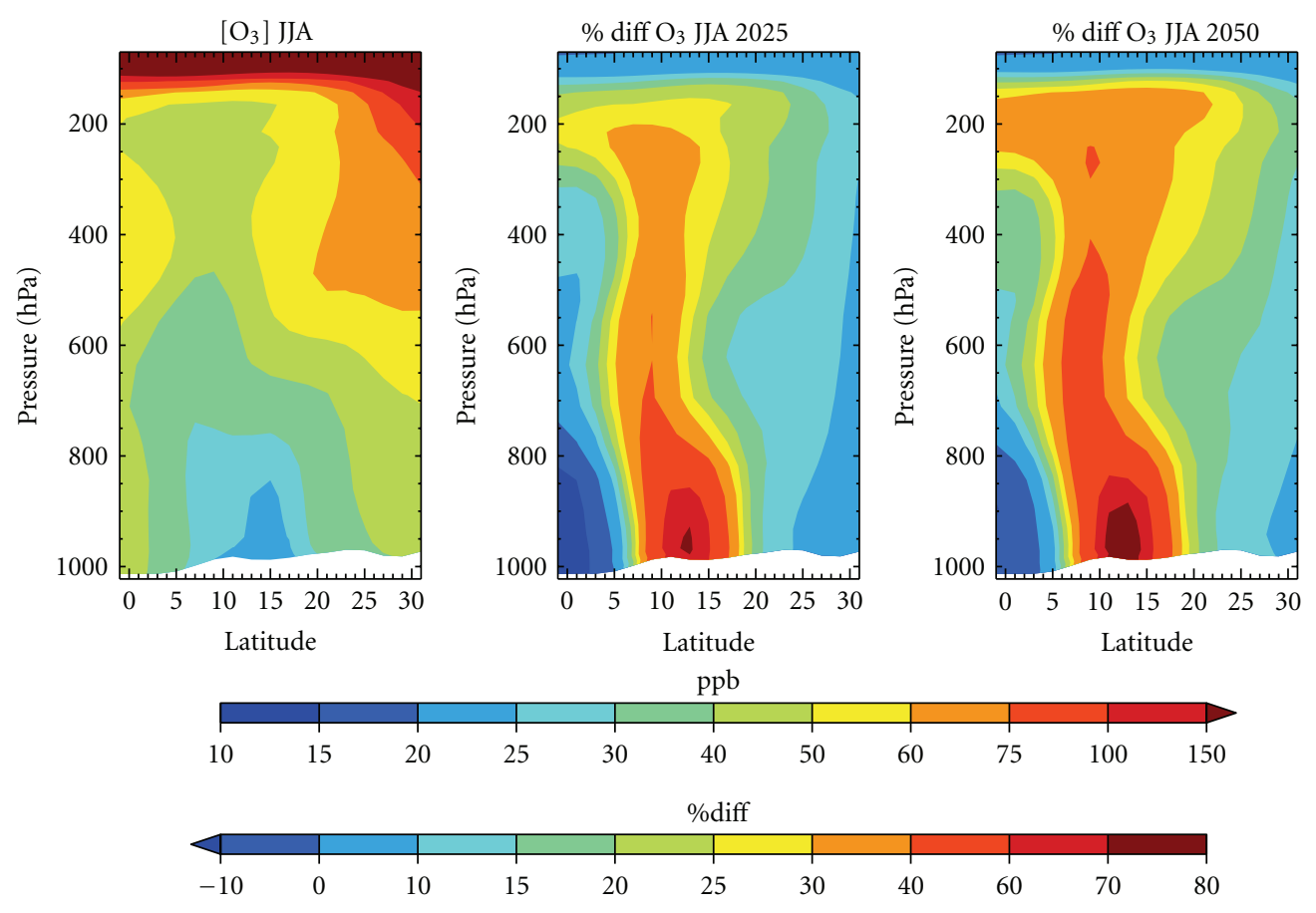

FIgURe 3: The seasonal zonal mean of tropospheric $\mathrm{O}_{3}$ over West Africa during JJA during 2003 averaged between $23^{\circ} \mathrm{W}-10^{\circ} \mathrm{E}$. Percentage differences are shown when compared against the A1B 2025 (middle) and A1B 2050 (right) simulations.

which a decrease of a few percent occurs. For the B1 scenario, there is a much lower rate of increase in the non-transport component by 2025 , being $\sim 20 \%$ lower than for the A1B. The differences between emission scenarios then fall to $~ 5 \%$ by 2050 .

For the transport $\mathrm{NO}_{x}$ emissions in and around WA, the contribution due to regional shipping dominates during 2003 , which is in contrast to the pattern at global scale where road transport is the dominant transport emission source [17]. The contribution due to shipping continues to increase across the entire timeline, increasing by $\sim 100 \%(\sim 20 \%)$ for the A1B (B1) scenarios at 2050. For road transport, a maximum occurs in 2025 in the A1B scenario, followed by a significant decrease in 2050 as a result of the introduction of mitigation technology (although the total number of vehicles is thought to increase). Thus, by 2050, road transport becomes the lowest transport $\mathrm{NO}_{x}$ emission source for WA. For the B1 scenario, a steady decrease is projected to occur along the whole timeline, again making the lowest relative contribution across all sectors by 2050 [19]. The smallest contribution from the transport sector is due to air traffic, where values are scaled up by 20 in Figure 2(b) for clarity. However, the influence of the resulting $\mathrm{O}_{3}$ formed by aircraft $\mathrm{NO}_{x}$ in terms of RF has been shown to be relatively large for air traffic as the emissions are injected directly into the upper troposphere [28]. Again this is different to the future emission trends at global scale, which show that shipping and road become approximately equal in 2025 and invert for 2050.

It should be noted that due to changes in the efficiency of $\mathrm{NO}_{x}$ recycling in a future atmosphere as a result of increasing background $\mathrm{CH}_{4}$ concentrations, the net production efficiency of $\mathrm{O}_{3}$ per molecule of $\mathrm{NO}_{x}$ increases regardless of decreases in $\mathrm{NO}_{x}$ emissions (see below). At the global scale, the influence of road transport on tropospheric composition has been found to be most important [28]. However, the fact that shipping emissions dominate for the WA region suggests that the regional RF is also influenced significantly by this transport sector.

\section{Increases in Seasonal Tropospheric $\mathrm{O}_{3}$ over West Africa}

Here, we focus our analysis on the monsoon season (JJA) thus minimizing the influence of $\mathrm{BB}$ in WA [22]. Figure 3 shows the zonal mean distribution in tropospheric $\mathrm{O}_{3}$ during JJA between $0^{\circ}-30^{\circ} \mathrm{N}$ for JJA during 2003. The mean values are averaged between $23^{\circ} \mathrm{W}-10^{\circ} \mathrm{E}$ to obtain the zonal mean so as to include only the emission sources in WA. It can be seen that the mixing ratios in the LT between $5-20^{\circ} \mathrm{N}$ are quite low ( $\sim 20-40 \mathrm{ppb})$, where the latitudinal variability in the zonal mean has features similar to those observed by airborne observations [29]. For latitudes nearer to the equator and above $20^{\circ} \mathrm{N}$, the mixing ratios increase to $>50 \mathrm{ppb}$ due to the influence of BB in southern Africa and influx from Europe, respectively.

Regarding the performance of TM4, past studies have shown that the accuracy of the model in the WA region is heavily constrained by the quality of the meteorological fields used to drive the model, where undersampling of atmospheric parameters can lead to deficiencies in, for 

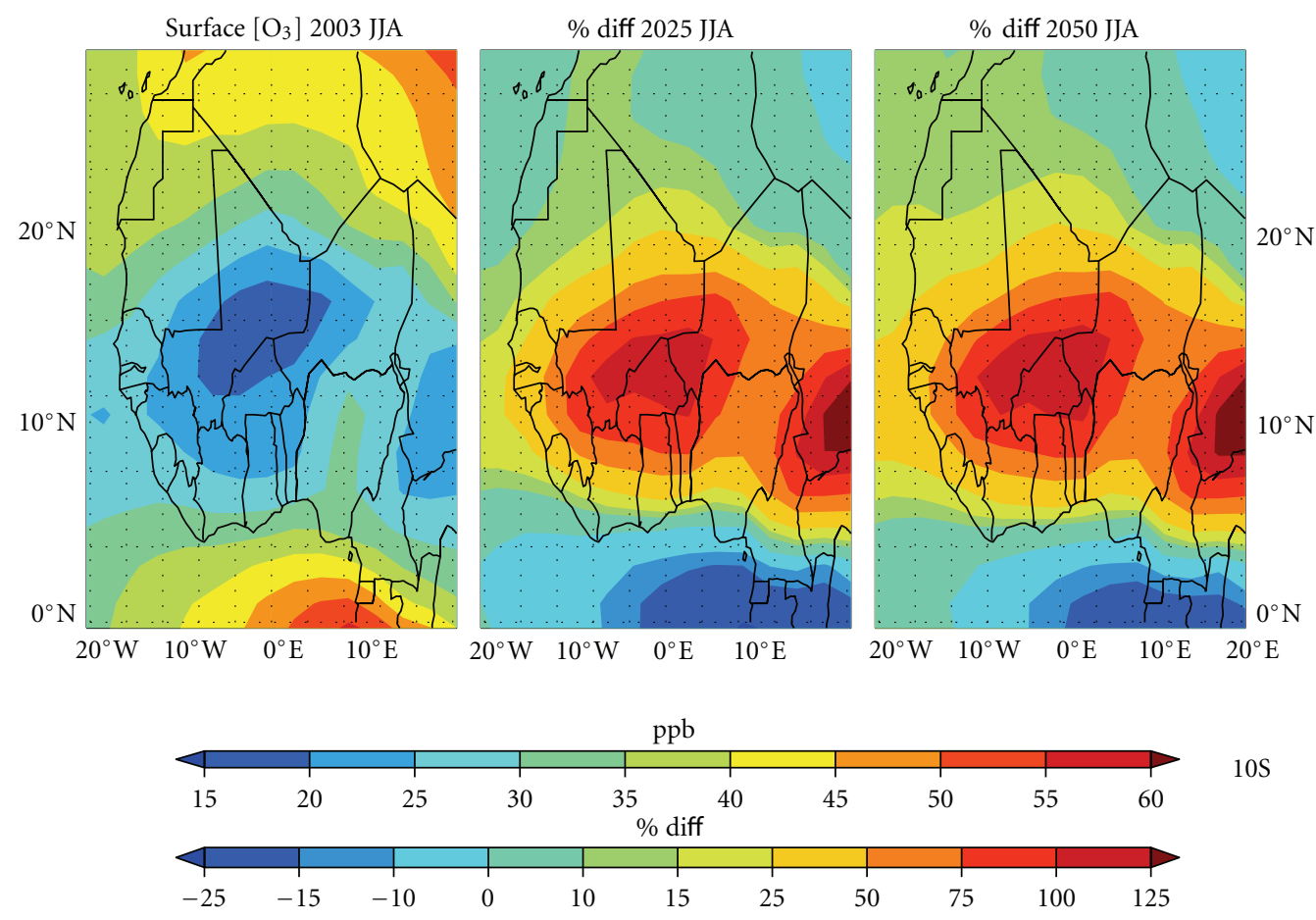

FIgURE 4: Seasonal mean of tropospheric $\mathrm{O}_{3}$ in the lowest $\mathrm{km}$ of the atmosphere for JJA during 2003 over West Africa. Percentage differences are shown when compared against the A1B 2025 (middle) and A1B 2050 (right) simulations.

example, the location of the African Easterly Jet-North $\left(\right.$ AEJ-N) $[4,8]$. Comparisons of colocated $\mathrm{O}_{3}$ profiles made against ozonesondes taken on the coast in Benin show that the mixing ratios in the middle troposphere are generally underpredicted for JJA [4], although capturing the correct airflow on the land-sea boundary is difficult in coarse CTMs. For locations further in land, comparisons made against a number of different aircraft measurements for August have shown better agreement throughout the troposphere [8]. For the UT, TM4 has been shown to capture the latitudinal gradient in UT $\mathrm{O}_{3}$ rather well [7]. These previous studies provide some confidence that TM4 can capture the correct zonal distribution of tropospheric $\mathrm{O}_{3}$ fairly well.

The associated percentage increases for the $\mathrm{A} 1 \mathrm{~B}$ scenario simulations for 2025 (middle) and 2050 (top) are also shown. For the upper troposphere (UT), changes in chemical composition are influenced by both convective uplift of airmasses from Central Africa [30] and long-range transport of chemically processed air-masses from, for example, India and Asia which enter the region via the Tropical Easterly Jet (TEJ) [31]. The largest increases occur in the LT between $7-15^{\circ} \mathrm{N}$, directly above and to the north of where the main anthropogenic $\mathrm{NO}_{x}$ emissions are released (c.f. Figure 1).

Strong convective transport lofts $\mathrm{NO}_{x}$ and $\mathrm{O}_{3}$ precursors upward out of the boundary layer into the free troposphere, causing enhanced tropospheric $\mathrm{O}_{3}$ formation in the outflow of convective systems and the African UT (e.g., [7, 31]). This increase subsequently imposes an associated perturbation in the RF in the UT [16]. Such perturbations in RF have the potential to both modify large-scale circulation by altering transport pathways (convection, Hadley and Brewer Dobson circulations), change the temperature of the tropopause and the altitude of the cold point. Moreover, when accounting for chemical processes important for the lower stratosphere (LS), increases in UT $\mathrm{O}_{3}$ are typically accompanied by reductions in $\mathrm{LS}_{3}$ [13]. This would further modify the associated potential chemistry-climate feedbacks.

The corresponding changes that occur in the lowest kilometer of the atmosphere are shown in Figure 4. For the present day, a minimum in $\mathrm{O}_{3}$ mixing ratios occurs over a wide region between $7-20^{\circ} \mathrm{N}$. Moving northward of $5^{\circ} \mathrm{N}$, there are both decreasing $\mathrm{NO}_{x}$ emissions and a change in the vegetation type which enhances the dry deposition of $\mathrm{O}_{3}$. Observations show that such a distribution is realistic, where the present-day surface $\mathrm{O}_{3}$ mixing ratios are relatively low between $10-15^{\circ} \mathrm{N}(<25 \mathrm{ppbv})$ [29]. Around the equator, the transport of polluted air from BB in southern Africa causes increases in near surface mixing ratios around $40-55 \mathrm{ppb}$.

Comparing the future simulations shows that the largest increases in near surface $\mathrm{O}_{3}$ occur over Nigeria, southern Mali, and Burkina Faso, which increases the near surface $\mathrm{O}_{3}$ mixing ratios to $\sim 40 \mathrm{ppb}$. These large increases are situated above the anthropogenic non-transport emission sources, where the increases also extend northwards due to the atmospheric wind circulation in the lower atmosphere transporting both $\mathrm{O}_{3}$ and its precursors inland [32]. Additional sensitivity studies (not shown) which apply $\sim 5 \%$ decrease on each of the transport sectors reveal that the shipping sector makes a significantly contribution to $\mathrm{O}_{3}$ formation $(\sim 5-$ $10 \%)$ up the west coast of Africa in the shipping route to 

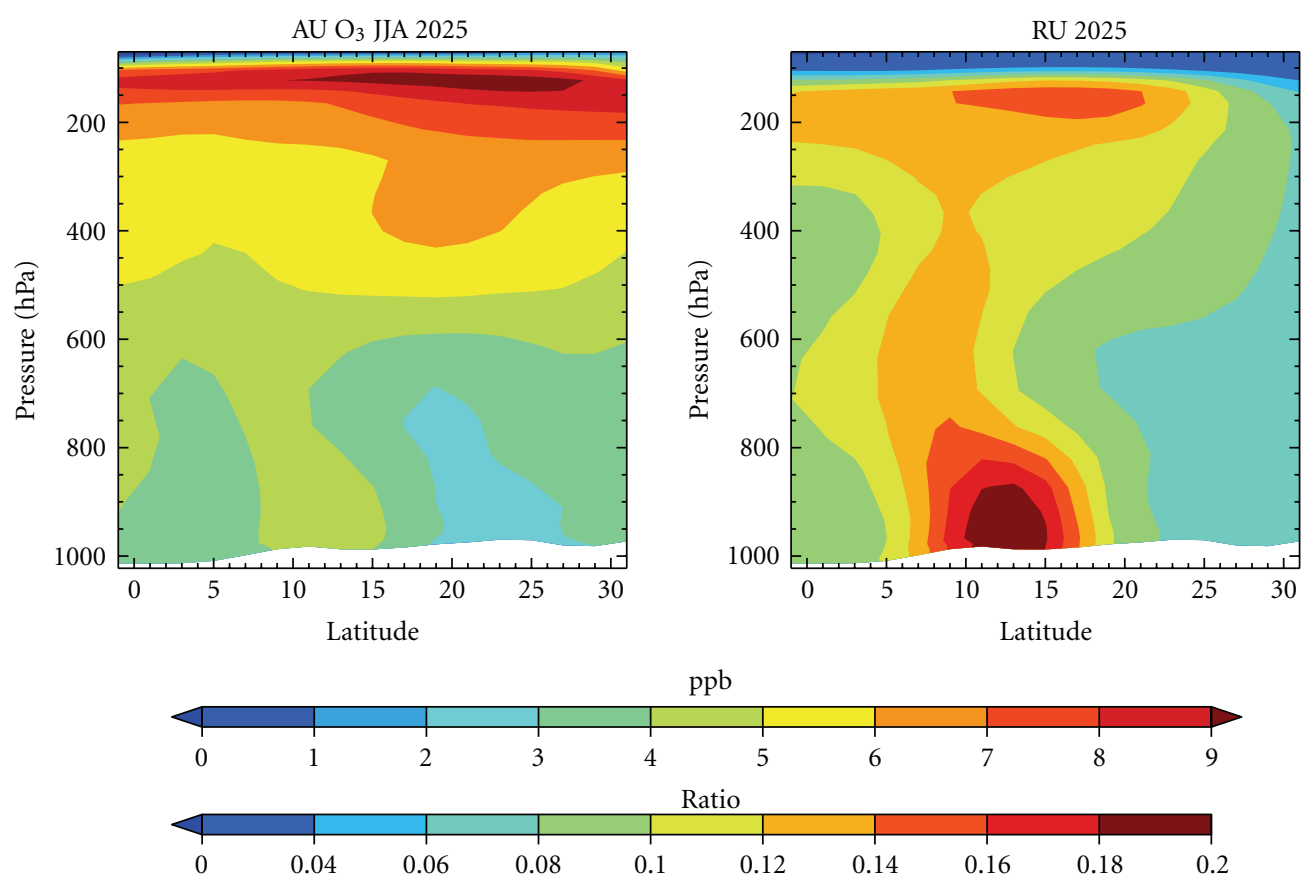

FIGURE 5: The zonal seasonal mean AU and RU between the A1 and B1 emission scenarios for 2025 during JJA. The uncertainty ratio represents the $1-\sigma$ variability weighted by the zonal seasonal mean distribution of tropospheric $\mathrm{O}_{3}$ for 2003 .

Europe, which then affects the background in the Sahel and Sahara by advection inland. Increases due to road transport are limited to between $\sim 2-4 \%$, where there is a signature from the North due to transport in North Africa and the Middle East. The highest increases in surface $\mathrm{O}_{3}(\sim 100 \%)$ are associated with regions which exhibit relatively low mixing of the order of $15-20 \mathrm{ppb}$ (e.g., $10-15^{\circ} \mathrm{N}, 0-10^{\circ} \mathrm{W}$ ). Near the equator, where near surface $\mathrm{O}_{3}$ is affected by southern $\mathrm{BB}$, decreases of between $15-25 \%$.

As the timeline progresses, increases of $\sim 10-15 \%$ occur further northward into Saharan Africa due to the continually increasing shipping emissions (Figure 2). Thus, near surface $\mathrm{O}_{3}$, in the future, may reach values typically found in more polluted regions such as Europe, which has negative consequences for, for example, crop yields and vegetation [33].

In part, the increase in tropospheric $\mathrm{O}_{3}$ is caused by enhanced $\mathrm{NO}_{x}$ recycling due to higher background $\mathrm{CH}_{4}$ in a future atmosphere [34] via the following cycle:

$$
\begin{gathered}
\mathrm{O}_{3}+h v\left(+\mathrm{H}_{2} \mathrm{O}\right) \longrightarrow 2 \mathrm{OH} \\
\mathrm{OH}+\mathrm{CH}_{4}\left(+\mathrm{O}_{2}\right) \longrightarrow \mathrm{H}_{2} \mathrm{O}+\mathrm{CH}_{3} \mathrm{O}_{2} \\
\mathrm{NO}+\mathrm{CH}_{3} \mathrm{O}_{2} \longrightarrow \mathrm{NO}_{2}+\mathrm{HCHO}+\mathrm{HO}_{2} \\
\mathrm{NO}+\mathrm{HO}_{2} \longrightarrow \mathrm{NO}_{2}+\mathrm{OH} \\
\mathrm{NO}_{2}+h v\left(+\mathrm{O}_{2}\right) \longrightarrow \mathrm{O}_{3}
\end{gathered}
$$

There is the additional feedback in that increasing $\mathrm{O}_{3}$ enhances $\mathrm{OH}$ production as a result of a faster net rate of reaction (1), thus modifying oxidizing capacity. Examining the chemical budget shows that for future atmospheres the net loss of $\mathrm{OH}$ by oxidation of $\mathrm{CO}$ only increases marginally compared to net loss via reaction (2). However, the chain length for the $\mathrm{NO}_{x}$ recycling mechanism is limited somewhat due to a larger fraction of the available nitrogen being converted into $\mathrm{HNO}_{3}$, which is subsequently lost by dry/wet deposition processes in the lower LT. Possible increases in precipitation frequency and intensity due to a changing climate could introduce more efficient loss than accounted for in this study, although the increasing importance of soil $\mathrm{NO}_{x}$ emissions in the presence of increasing precipitation would buffer this loss to a certain degree [9].

\section{Uncertainty in Future $\mathrm{O}_{3}$ Increases due to Anthropogenic Emission Sources}

In this section, we investigate the uncertainty introduced with respect to the distribution of future tropospheric $\mathrm{O}_{3}$ over WA as a result of applying the different projections for the evolution of anthropogenic $\mathrm{NO}_{x}$ emissions over the chosen timeline. For this purpose, we show both the Absolute Uncertainty (AU), defined as the difference in the tropospheric $\mathrm{O}_{3}$ distribution between the $\mathrm{A} 1 \mathrm{~B}$ and $\mathrm{B} 1$ scenarios, and the Relative Uncertainty (RU), defined as the AU divided by the present day distribution.

Figure 5 shows the AU (left) and RU (right) for the zonal seasonal mean during JJA above WA for 2025. The AU for 2025 in the LT shows that as well as the uncertainty introduced by the differences in the non-transport $\mathrm{NO}_{x}$ emissions, there is a signature from the shipping sector. This 


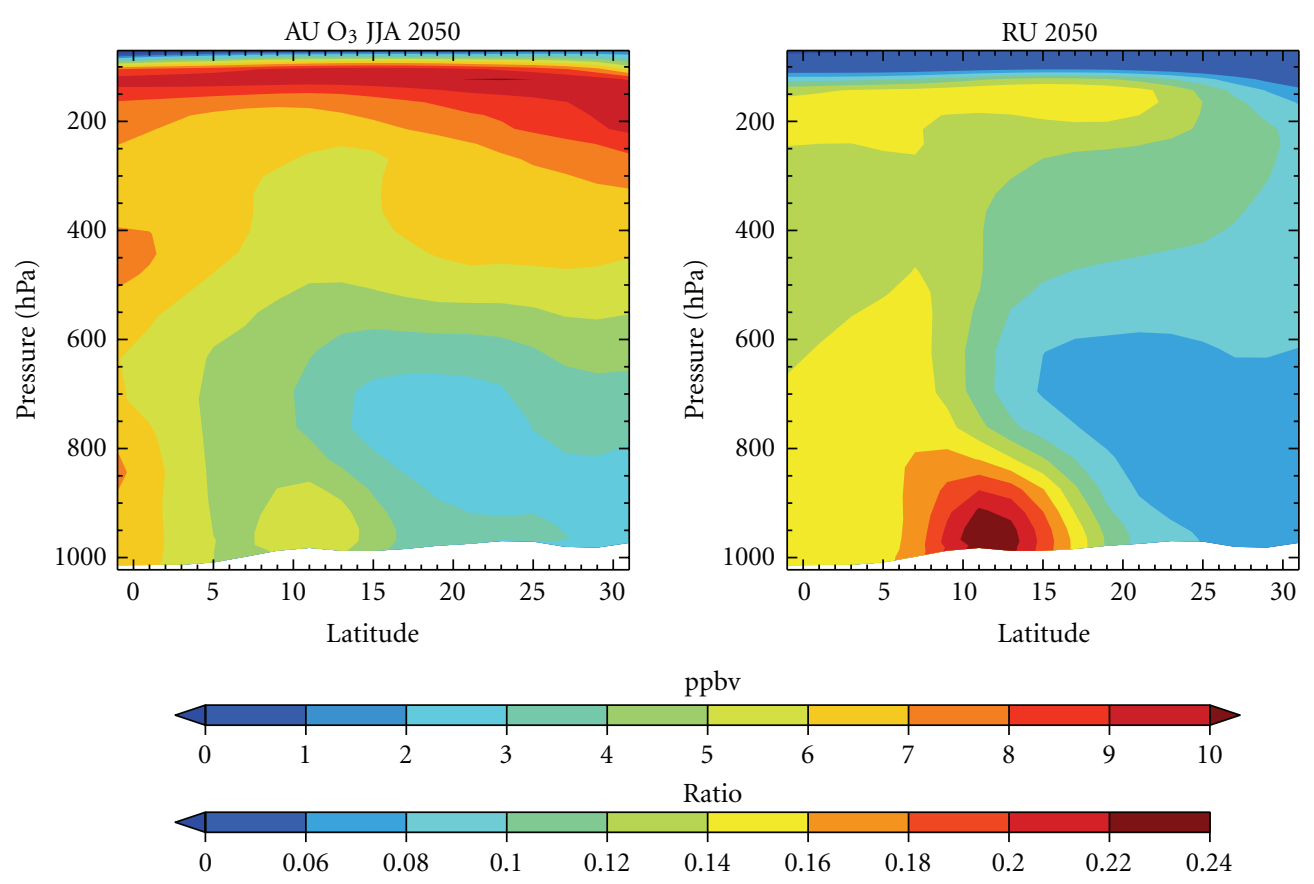

Figure 6: As for Figure 5 except for 2050.

results in an uncertainty of around $\sim 8-10 \%$ in near surface $\mathrm{O}_{3}$ over the tropical Atlantic Ocean between $0-5^{\circ} \mathrm{N}$. However, it should be noted that these simulations do not account for subgrid processes such as plume chemistry, which has been shown to modify the resulting $\mathrm{O}_{3}$ distribution when applied to the release of, for example, aircraft emissions [35], reducing the efficiency of $\mathrm{O}_{3}$ production. The effect of convective uplift of $\mathrm{NO}_{x}$ precursors can be seen directly above the main non-transport source regions. For the UT, the AU becomes more homogeneous with respect to latitude due to the influence of long-range transport of elevated $\mathrm{O}_{3}$ into the region (see below). The distribution of RU shows that the uncertainty in the UT is relatively high, with a larger uncertainty occurring towards the tropics. In terms of RF, this is the most important uncertainty due to the largest perturbations being caused by changes in $\mathrm{O}_{3}$ which occur in the UT [36].

In Figure 6, we show the corresponding differences for 2050. Although the AU is of the same order of magnitude as that shown for 2025, the largest differences occur nearer to the equator, with the uncertainty in the LT north of $20^{\circ} \mathrm{N}$ dropping to below $\sim 12 \%$. This is due to the difference in the non-transport $\mathrm{NO}_{x}$ emissions decreasing between the emission scenarios (c.f. Figure 2(a)) and due to the strong mitigation practices that have occurred in Europe and North Africa between 2025 and 2050 (not shown), which reduces influx of $\mathrm{O}_{3}, \mathrm{O}_{3}$ precursors, and $\mathrm{CO}$ into the region. For the RU, the largest uncertainty is again directly above the source regions of the non-transport emissions, but there is an increase in the uncertainty towards the equator again due to the increasing shipping emissions.
Finally, in Figure 7, we show the seasonal distribution of tropospheric $\mathrm{O}_{3}$ between 150-200 hPa over WA, along with the corresponding RU for 2025 and 2050. The signature in the UT RU values due to convective uplift of boundary layer air over WA becomes less obvious at 2050, where it is rather the influence of polluted air transported from Asia which results in the higher uncertainty towards the east (not shown) [31]. Therefore, this implies that the largest uncertainty in the UT is most likely related to the large uncertainties associated with future Asian emission inventories.

The uncertainties in future tropospheric $\mathrm{O}_{3}$ distributions presented here rely somewhat on the quality of the presentday emission inventories, the meteorological data used to drive the model, the chemical mechanism employed, and whether the estimates in future anthropogenic emissions are accurate. At the current time, large-scale global chemistry transport models do have problems being able to capture the small scale variability and the correct horizontal and vertical distribution of tropospheric $\mathrm{O}_{3}$ for the region [8]. For instance, one main deficiency for WA is that the transport of pollutants towards the West during the monsoon is not optimal, which will most likely affect the distribution of AU and RU shown in Figures 5-7. Quantifying this additional uncertainty is not currently feasible as it would require extensive comparisons of modeled $\mathrm{O}_{3}$ against an observational dataset available for the entire season. To date measurements in Africa are only available at few locations usually situated near urban centres, making extensive model validation for any arbitrary year very difficult. It should also be noted that performing such simulations at a higher horizontal resolution of, for example, $1^{\circ} \times 1^{\circ}$ would also alter 

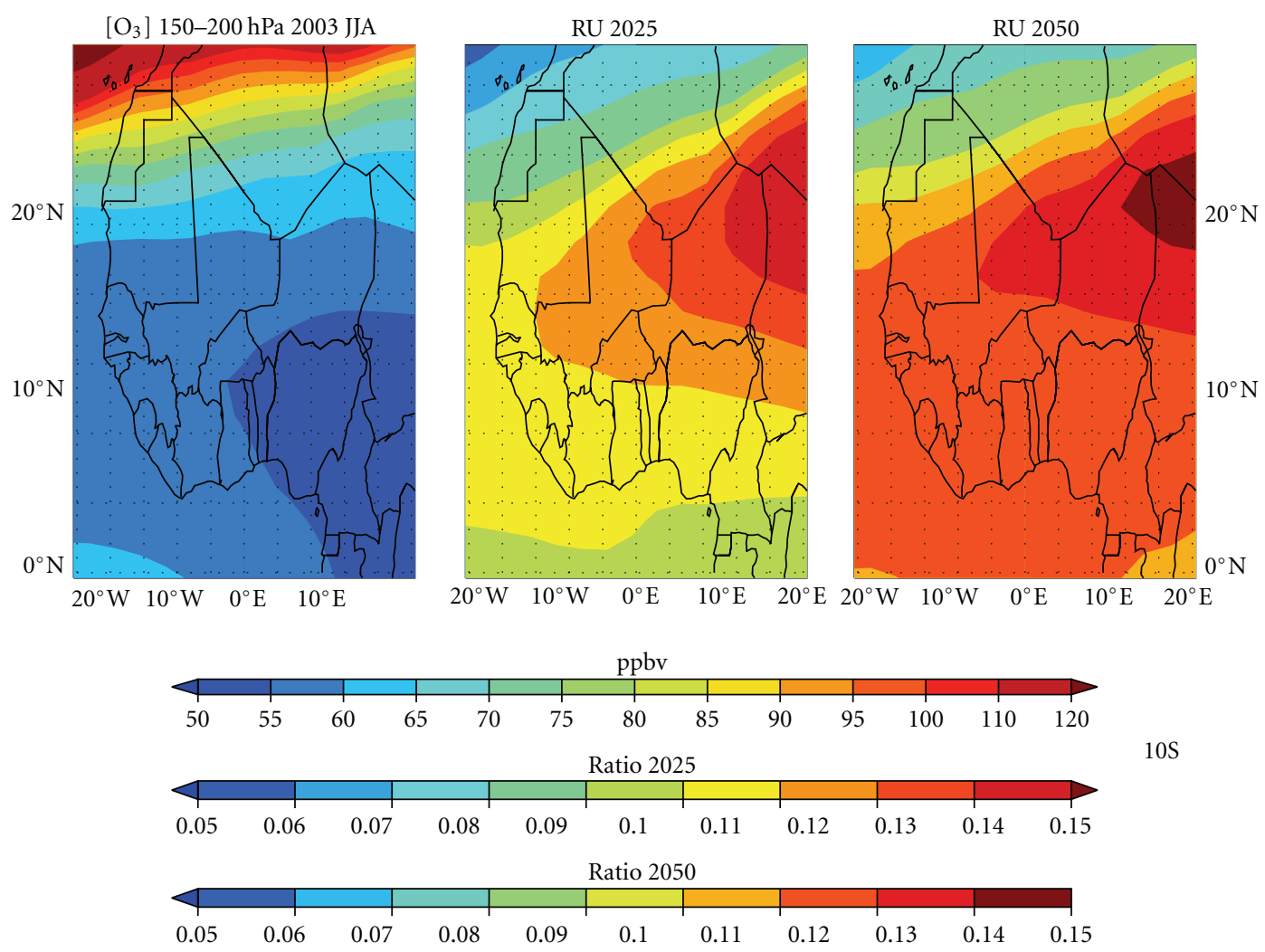

Figure 7: The seasonal distribution of tropospheric $\mathrm{O}_{3}$ between 150-200 hPa over West Africa. The corresponding RU is shown for both 2025 (middle) and 2050 (right).

the results due to the dependency of $\mathrm{O}_{3}$ formation on model configuration [35].

\section{Conclusions}

Analysing the trends in future anthropogenic emission scenarios for the West African region $\left(0-30^{\circ} \mathrm{N}, 20^{\circ} \mathrm{W}-10^{\circ} \mathrm{E}\right)$ reveals that significant differences exist for $\mathrm{NO}_{x}$ between a "business-as-usual" scenario (A1B) and a "clean economy" scenario (B1), where differences of $\sim 20 \%$ in the emissions from non-transport based sources are projected for 2025, which diminish to $\sim 5 \%$ at 2050 . In contrast to the global emission estimates, $\mathrm{NO}_{x}$ emissions from shipping were found to dominate for the transport sector over the timeline 2000-2050, where a significant reduction in $\mathrm{NO}_{x}(\sim 80 \%)$ is envisaged for road transport, regardless of the emission scenario adopted.

By applying these emission estimates in 3D global chemistry-transport simulations, we have shown that for the most realistic emission scenario (A1B), there are significant increases in tropospheric $\mathrm{O}_{3}$ over West Africa throughout the troposphere. This will have important implications for radiative forcing, surface air quality, the oxidizing potential of the atmosphere, and on transport in the westerly outflow. Examining the chemical budget reveals that, in part, this increase in $\mathrm{O}_{3}$ is due to more efficient $\mathrm{NO}_{x}$ recycling from the projected increase in the background methane concentrations. At the surface, the largest increases in near surface $\mathrm{O}_{3}$ occur between $10-15^{\circ} \mathrm{N}$ near the non-transport emission sources for both 2025 and 2050. It is shown that the projected increases in anthropogenic $\mathrm{NO}_{x}$ emissions will significantly degrade air quality over a wide region in the near future. By calculating the uncertainty in the distribution of tropospheric $\mathrm{O}_{3}$ from the application of the different emission inventories, we find that the uncertainty over the region is $\sim 20 \%$, with a higher uncertainty for the lower troposphere over the locations containing strong emission sources and towards the equator due to shipping. For 2050, the largest absolute uncertainty shifts towards the equator due to the strong mitigation of anthropogenic emissions in Europe and the increasing importance of shipping emissions. For the UT, a larger uncertainty exists related to the longrange transport of polluted air from Asia carried into the region in the Tropical Easterly Jet and the difference in the projected increase in future Asian emissions between scenarios.

\section{Acknowledgments}

J. E. Williams acknowledges partial financial support from the EU-integrated 6th framework research project QUANTIFY (contract 003893), also for providing access to the future emission inventories. The authors also thank A. Strunk for help with the IDL programming. 


\section{References}

[1] J. R. Hopkins, M. J. Evans, J. D. Lee et al., "Direct estimates of emissions from the megacity of Lagos," Atmospheric Chemistry and Physics, vol. 9, no. 21, pp. 8471-8477, 2009.

[2] SWAC/OECD and Economic Community of West African States, Western African Perspectives, OECD publishing, 2009.

[3] S. E. Nicholson and J. P. Grist, "The seasonal evolution of the atmospheric circulation over West Africa and equatorial Africa," Journal of Climate, vol. 16, no. 7, pp. 1013-1030, 2003.

[4] J. E. Williams, M. P. Scheele, P. F. J. van Velthoven, V. Thouret, M. Saunois, and C. E. Reeves, "The influence of biomass burning and transport on tropospheric composition over the tropical Atlantic Ocean and Equatorial Africa during the West African monsoon in 2006," Atmospheric Chemistry and Physics, vol. 10, no. 20, pp. 9797-9817, 2010.

[5] J. L. Redelsperger, C. D. Thorncroft, A. Diedhiou, T. Lebel, D. J. Parker, and J. Polcher, "African Monsoon Multidisciplinary Analysis: an international research project and field campaign," Bulletin of the American Meteorological Society, vol. 87, no. 12, pp. 1739-1746, 2006.

[6] P. M. Ruti, J. E. Williams, F. Hourdin et al., "The West African climate system: a review of the AMMA model intercomparison initiatives," Atmospheric Science Letters, vol. 12, pp. 116-122, 2011.

[7] B. Barret, J. E. Williams, I. Bouarar et al., "Impact of West African Monsoon convective transport and lightning $\mathrm{NO}_{\mathrm{x}}$ production upon the upper tropospheric composition: a multi-model study," Atmospheric Chemistry and Physics, vol. 10, no. 12, pp. 5719-5738, 2010.

[8] J. E. Williams, R. Scheele, P. van Velthoven et al., "Global chemistry simulations in the amma multimodel intercomparison project," Bulletin of the American Meteorological Society, vol. 91, no. 5, pp. 611-624, 2010.

[9] J. E. Williams, M. P. Scheele, P. F. J. van Velthoven et al., "The influence of biogenic emissions from Africa on tropical tropospheric ozone during 2006: a global modeling study," Atmospheric Chemistry and Physics, vol. 9, no. 15, pp. 57295749, 2009.

[10] C. Liousse, B. Guillaume, J. M. Grégoire et al., "Updated African biomass burning emission inventories in the framework of the AMMA-IDAF program, with an evaluation of combustion aerosols," Atmospheric Chemistry and Physics, vol. 10, pp. 9631-9646, 2010.

[11] N. Nakicenovic, O. Davidson, G. Davis et al., Special Report on Emission Scenarios, Cambridge University Press, Cambridge, UK, 2000.

[12] R. Garnaut, S. Howes, F. Jotzo, and P. Sheehan, "Emissions in the platinum age: the implications of rapid development for climate-change mitigation," Oxford Review of Economic Policy, vol. 24, no. 2, pp. 377-401, 2008.

[13] M. Gauss, G. Myhre, I. S. A. Isaksen et al., "Radiative forcing since preindustrial times due to ozone change in the troposphere and the lower stratosphere," Atmospheric Chemistry and Physics, vol. 6, no. 3, pp. 575-599, 2006.

[14] S. Houweling, F. Dentener, and J. Lelieveld, "The impact of non-methane hydrocarbon compounds on tropospheric photochemistry," Journal of Geophysical Research, vol. 103, no. 3339, pp. 10673-10696, 1998.

[15] J. Landgraf and P. J. Crutzen, "An efficient method for online calculations of photolysis and heating rates," Journal of the Atmospheric Sciences, vol. 55, no. 5, pp. 863-878, 1998.
[16] G. Myhre, K. P. Shine, G. Rädel et al., "Radiative forcing due to changes in ozone and methane caused by the transport sector," Atmospheric Environment, vol. 45, no. 2, pp. 387-394, 2011.

[17] P. Hoor, J. Borken-Kleefeld, D. Caro et al., "The impact of traffic emissions on atmospheric ozone and $\mathrm{OH}$ : results from QUANTIFY," Atmospheric Chemistry and Physics, vol. 9, no. 9, pp. 3113-3136, 2009.

[18] J. G. J. Olivier, J. A. van Aardenne, F. Dentener, L. Ganzeveld, and J. A. H. W. Peters, "Recent trends in global greenhouse emissions: regional trends and spatial distribution of key sources," in Non- $\mathrm{CO}_{2}$ Grehouse Gases (NCGG-4), pp. 325-330, Millpress, Rotterdam, The Netherlands, 2005.

[19] E. Uherek, T. Halenka, J. Borken-Kleefeld et al., "Transport impacts on atmosphere and climate: land transport," Atmospheric Environment, vol. 44, no. 37, pp. 4772-4816, 2010.

[20] O. Endresen, E. Sorgard, H. L. Behrens, P. O. Brett, and I. S. A. Isaksen, "A histrotical reconstruction of ships fuel consumption and emissions," Journal of Geophysical Research, vol. 112, p. 17, 2007.

[21] B. Owen, D. S. Lee, and L. Lim, "Flying into the future: aviation emissions scenarios to 2050," Environmental Science and Technology, vol. 44, no. 7, pp. 2255-2260, 2010.

[22] G. R. van der Werf, J. T. Randerson, L. Giglio, G. J. Collatz, P. S. Kasibhatla, and A. F. Arellano, "Interannual variability in global biomass burning emissions from 1997 to 2004," Atmospheric Chemistry and Physics, vol. 6, no. 11, pp. 34233441, 2006.

[23] P. Jöckei, H. Tost, A. Pozzer et al., "The atmospheric chemistry general circulation model ECHAM5/MESSy1: consistent simulation of ozone from the surface to the mesosphere," Atmospheric Chemistry and Physics, vol. 6, no. 12, pp. 50675104, 2006.

[24] F. Dentener, S. Kinne, T. Bond et al., "Emissions of primary aerosol and precursor gases in the years 2000 and 1750 prescribed datasets for Aerocom," Atmospheric Chemistry and Physics, vol. 6, no. 12, pp. 4321-4344, 2006.

[25] U. Schumann and H. Huntrieser, "The global lightninginduced nitrogen oxides source," Atmospheric Chemistry and Physics, vol. 7, no. 14, pp. 3823-3907, 2007.

[26] I. J. Simpson, F. S. Rowland, S. Meinardi, and D. R. Blake, "Influence of biomass burning during recent fluctuations in the slow growth of global tropospheric methane," Geophysical Research Letters, vol. 33, Article ID L22808, 2006.

[27] J. T. Houghton, Y. Ding, D. Griggs et al., Eds., IPCC: Climate Change 2001: The Scientific Basis. Contribution of Working Group I to the Third Assessment Report of the Intergovernmental Panel on Climate Change, Cambridge University Press, Cambridge, UK, 2001.

[28] J. Fuglestvedt, T. Berntsen, G. Myhre, K. Rypdal, and R. B. Skeie, "Climate forcing from the transport sectors," Proceedings of the National Academy of Sciences of the United States of America, vol. 105, no. 2, pp. 454-458, 2008.

[29] C. E. Reeves, P. Formenti, C. Afif et al., "Chemical and aerosol characterisation of the troposphere over West Africa during the monsoon period as part of AMMA," Atmospheric Chemistry and Physics, vol. 10, no. 16, pp. 7575-7601, 2010.

[30] B. Barret, P. Ricaud, C. Mari et al., "Transport pathways of $\mathrm{CO}$ in the African upper troposphere during the monsoon season: a study based upon the assimilation of spaceborne observations," Atmospheric Chemistry and Physics, vol. 8, no. 12, pp. 3231-3246, 2008.

[31] K. S. Law, F. Fierli, F. Cairo et al., "Air Mass origins influencing TTL chemical composition over West Africa during 2006 
summer monsoon," Atmospheric Chemistry and Physics, vol. 10, no. 22, pp. 10753-10770, 2010.

[32] D. J. Parker, R. R. Burton, A. Diongue-Niang et al., "The diurnal cycle of the West African monsoon circulation," Quarterly Journal of the Royal Meteorological Society, vol. 131, pp. 2839-2860, 2005.

[33] F. L. Booker, R. Muntifering, M. Mcgrath et al., "The ozone component of global change: potential effects on agricultural and horticultural plant yield, product quality and interactions with invasive species," Journal of Integrative Plant Biology, vol. 51, no. 4, pp. 337-351, 2009.

[34] A. M. Fiore, J. J. West, L. W. Horowitz, V. Naik, and M. D. Schwartzkopf, "Characterising the tropospheric ozone response to methane emission controls and the benefits to climate and air quality," Journal of Geophysical Research, vol. 113, Article ID D08307, 16 pages, 2008.

[35] O. Wild and M. J. Prather, "Global tropospheric ozone modeling: quantifying errors due to grid resolution," Journal of Geophysical Research, vol. 111, no. 11, Article ID D11305, 2006.

[36] D. Cariolle, D. Caro, R. Paoli et al., "Parameterization of plume chemistry into large-scale atmospheric models: application to aircraft $\mathrm{NO}_{x}$ emissions," Journal of Geophysical Research, vol. 114, Article ID D19302, 21 pages, 2009. 

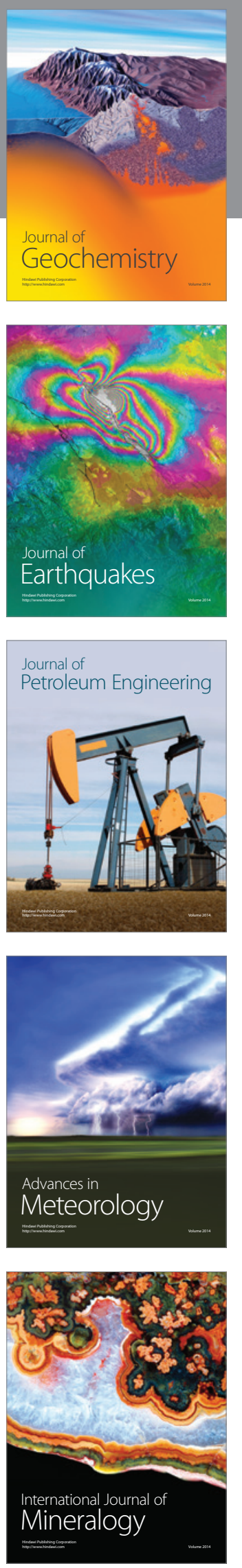
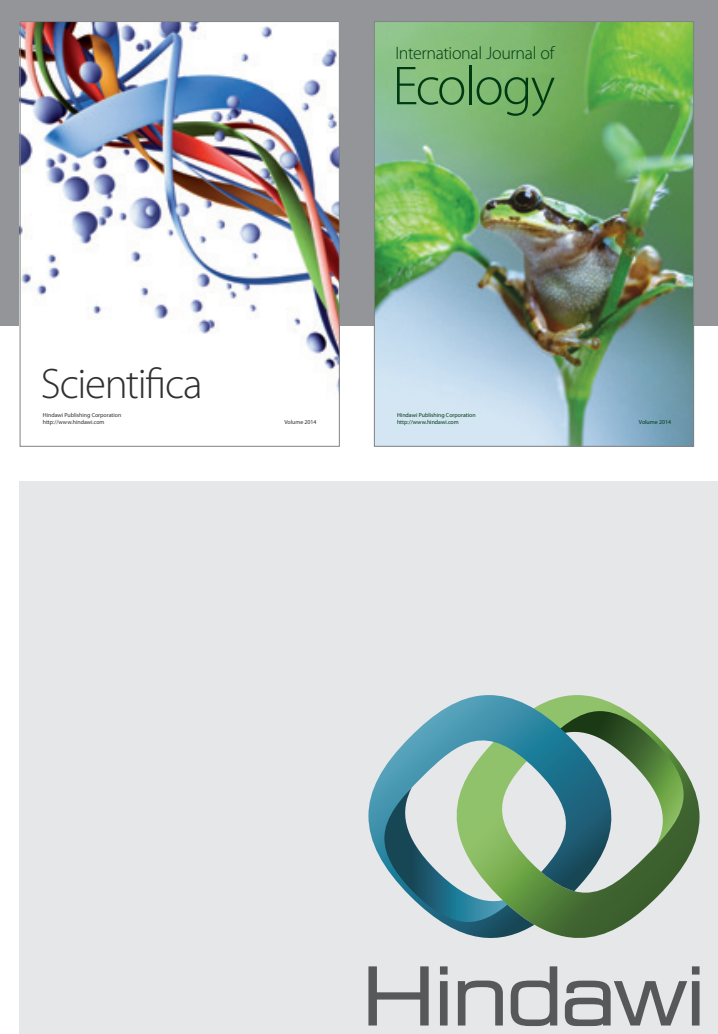

Submit your manuscripts at http://www.hindawi.com
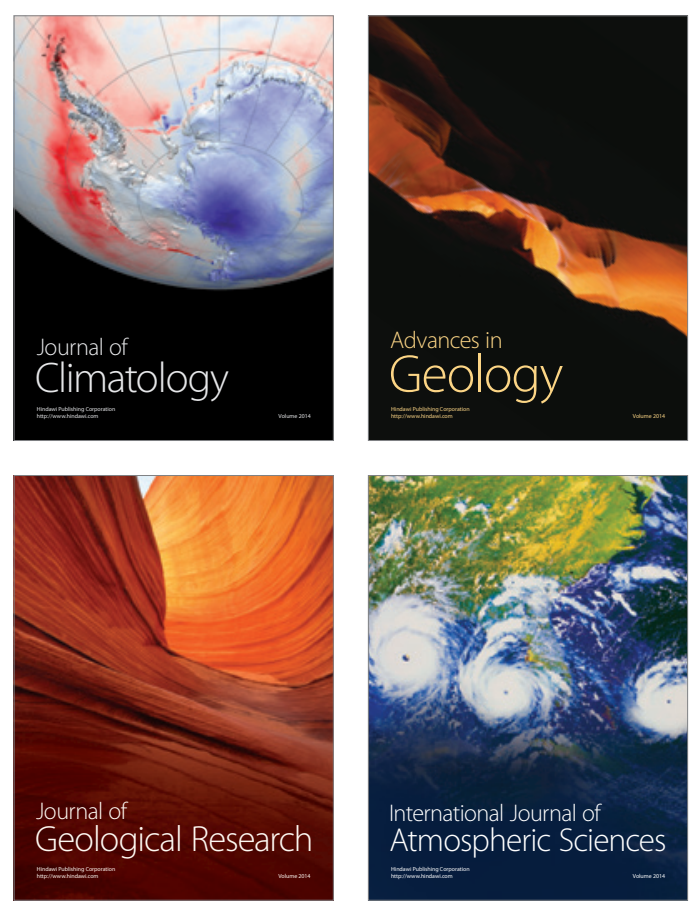
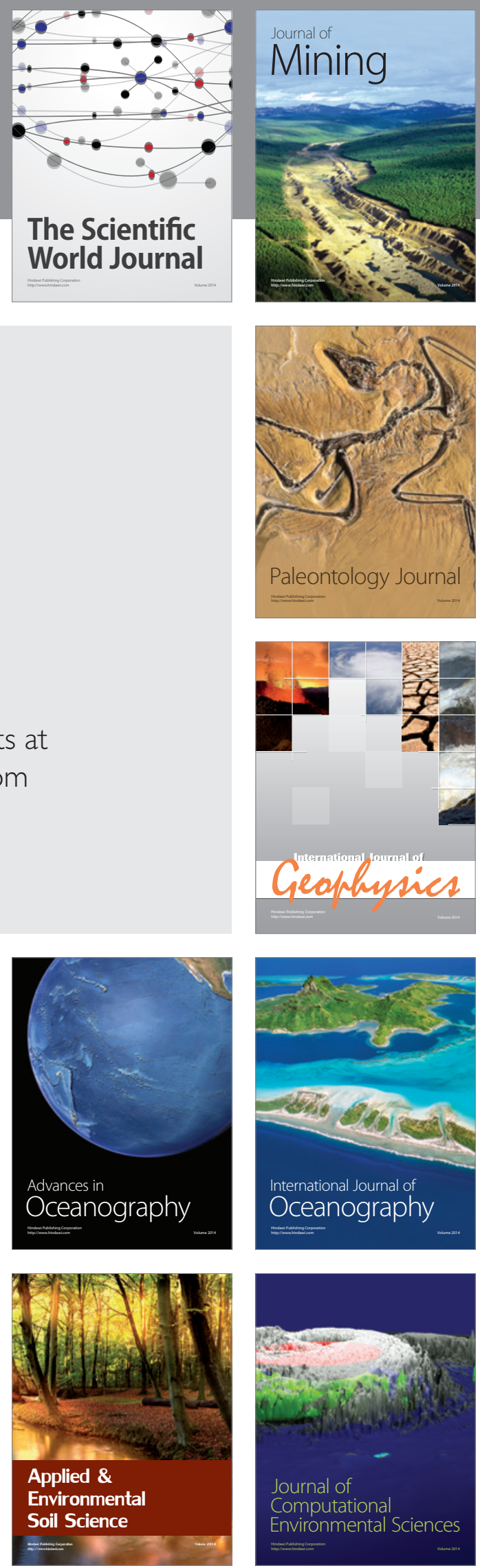